\title{
Erratum to: A pilot investigation of load-carrying on the head and bone mineral density in premenopausal, black African women
}

Ray Lloyd • Karen Hind • Lisa K. Micklesfield •

Sean Carroll · John G. Truscott · Bridget Parr •

Simeon Davies $\cdot$ Carlton Cooke

Published online: 29 October 2009

(C) The Japanese Society for Bone and Mineral Research and Springer 2009

Erratum to: J Bone Miner Metab

DOI 10.1007/s00774-009-0113-3

The correct name of the seventh author is Simeon Davies, not Simoene Davies.

The online version of the original article can be found under doi:10.1007/s00774-009-0113-3.

R. Lloyd

University of Abertay, Dundee DD1 1HG, UK

K. Hind $(\varangle) \cdot$ S. Carroll $\cdot$ C. Cooke

Carnegie Research Institute, Leeds Metropolitan University,

Headingley Campus, Leeds LS6 3QS, UK

e-mail: K.hind@leedsmet.ac.uk

L. K. Micklesfield

University of Cape Town, Newlands 7725, South Africa

J. G. Truscott

Division of Medical Physics, Worsley Building,

University of Leeds, Leeds LS2 9JT, UK

B. Parr · S. Davies

Cape Peninsula University of Technology,

Cape Town, South Africa 